\title{
Data Processing in the Pilot Training Process on the Integrated Aircraft Simulator
}

\author{
Yurii Hryshchenko (Associate professor, National Aviation University, Kyiv, Ukraine), \\ Maksym Zaliskyi ${ }^{*}$ (Associate professor, National Aviation University, Kyiv, Ukraine), \\ Svitlana Pavlova (Professor, National Aviation University, Kyiv, Ukraine), \\ Oleksandr Solomentsev (Professor, National Aviation University, Kyiv, Ukraine), \\ Tatiana Fursenko (Associate professor, National Aviation University, Kyiv, Ukraine)
}

\begin{abstract}
Flight safety is an integral part of air transportation. Flight accidents are highly unlikely to appear but most of them are caused by the human factor. The aircrew training system for abnormal operations relies on integrated aircraft simulator-based exercises. Crew needs to be trained not to degrade piloting technique quality when facing increased psychophysiological tension. Therefore, methods evaluating the characteristics of ergatic aircraft control systems, warning systems for deterioration due to failures in avionics systems, piloting technique quality, and abnormal operation algorithms are necessary. An analysis of the bank angle has revealed that there are hidden increased tension manifestations in the human operator expressed in the transition of the flight parameter variation from a stationary random process to deterministic fluctuations in the form of a sinusoid. The goal of the research is to increase the efficiency of pilots' training using integrated aircraft simulators based on the design and implementation of statistical data processing algorithms. To achieve the goal of the research, two algorithms for detecting deterministic fluctuations based on the Neyman-Pearson criterion and the optimal Bayesian criterion are developed. The presented algorithms can be used in the integrated simulator software to automate the decision-making process on piloting quality.
\end{abstract}

Keywords - Aircraft; Algorithm design and analysis; Data analysis; Detection algorithms; Human factors; Random processes; Training.

\section{INTRODUCTION}

Modern aircraft have highly reliable avionics and other systems [1]. Flight accidents are unlikely to take place. Aircraft control automation exempts the crew from routine actions and frees up time for decision-making. At the same time, the crew experiences increased psychophysiological tension when taking control in case of failures (malfunctions) in avionics systems and other equipment [2].

The process of flight personnel's training in civil aviation includes abnormal operation exercises on integrated aircraft simulators (IASs). It is very important to inculcate a consistent pattern of an action sequence in such situations [3]. However, the combination of several simultaneous failures cannot be worked through. On the Tu-154 B2 IAS, it was previously identified that $70 \%$ of pilots without special training have an increase in the amplitude of aircraft operation parameters (AAOPs) due to their increased psychophysiological tension in case of aircraft equipment simultaneous failures (two and more) [4]-[6].

Modern aircraft crew preparation should give training in adequate actions taken when negative factors occur simultaneously [7]. This is modelled by complex avionics failures (malfunctions) on an IAS.

To assess the characteristics of the ergatic aircraft control system, it is advisable to apply mathematical statistics, statistical decision theory, probability theory methods [8].

\section{LiterATURE REVIEW AND PROBLEM STATEMENT}

Crew needs to be trained not to degrade their piloting technique quality when facing increased psychophysiological tension. Therefore, it is necessary to develop methods evaluating the characteristics of ergatic aircraft control systems due to failures in avionics systems to objectively determine piloting technique quality during abnormal operations.

Distribution laws to describe all kinds of events are used in various fields of science - in ergonomics [9], the reliability theory of engineering systems [10]-[14].

The probability of an increase in AAOP occurrence is connected with aircraft equipment and avionics failures and malfunctions [15]. According to the laws of aircraft operation parameter distribution, the characteristics of the ergatic aircraft control system can be estimated. In [16]-[21], methods for distinguishing deterministic fluctuations in the form of a sinusoid from a stationary random process are described.

In this paper, based on the statistics of one of the important operation parameters on the An-148 IAS (bank angle), the problems of choosing the bank angle distribution law and algorithms for detecting the harmonic component in bank angle trends are solved.

The practical application of the above-mentioned algorithms and the corresponding methods based on them serves the purpose of piloting technique quality assessment in the ergatic control

\footnotetext{
* Corresponding author.

E-mail: mzaliskyi@nau.edu.ua
}

(C)2021 Yurii Hryshchenk, Maksym Zaliskyi, Svitlana Pavlova, Oleksandr Solomentsev, Tatiana Fursenko. 
system of modern aircraft. The algorithms developed in the article are related to solving statistical data processing problems. For illustrative purposes, Fig. 1 shows the implementation of a number of operation parameters on the An-148 IAS. These implementations correspond to the case when there are several failures in the aircraft avionics system. Figure 1 shows that the realisations are stochastic in nature.

There are often hidden increased tension manifestations in the human operator, which are expressed in the transition from a stationary random process to deterministic fluctuations in the form of a sinusoid. Sometimes this is not accompanied by an increase in the amplitude of parameters. This is due to the fact that with further exposure to other negative factors, the values of the amplitude of parameters significantly increase.

Taking into account the goal of the research, the following objectives need to be considered:

1) analysis of bank angle trends with no equipment failures;

2) analysis of bank angle trends in case of equipment failures;

3 ) synthesis and analysis of data processing algorithms for detecting a deterministic fluctuation in the bank angle trend.

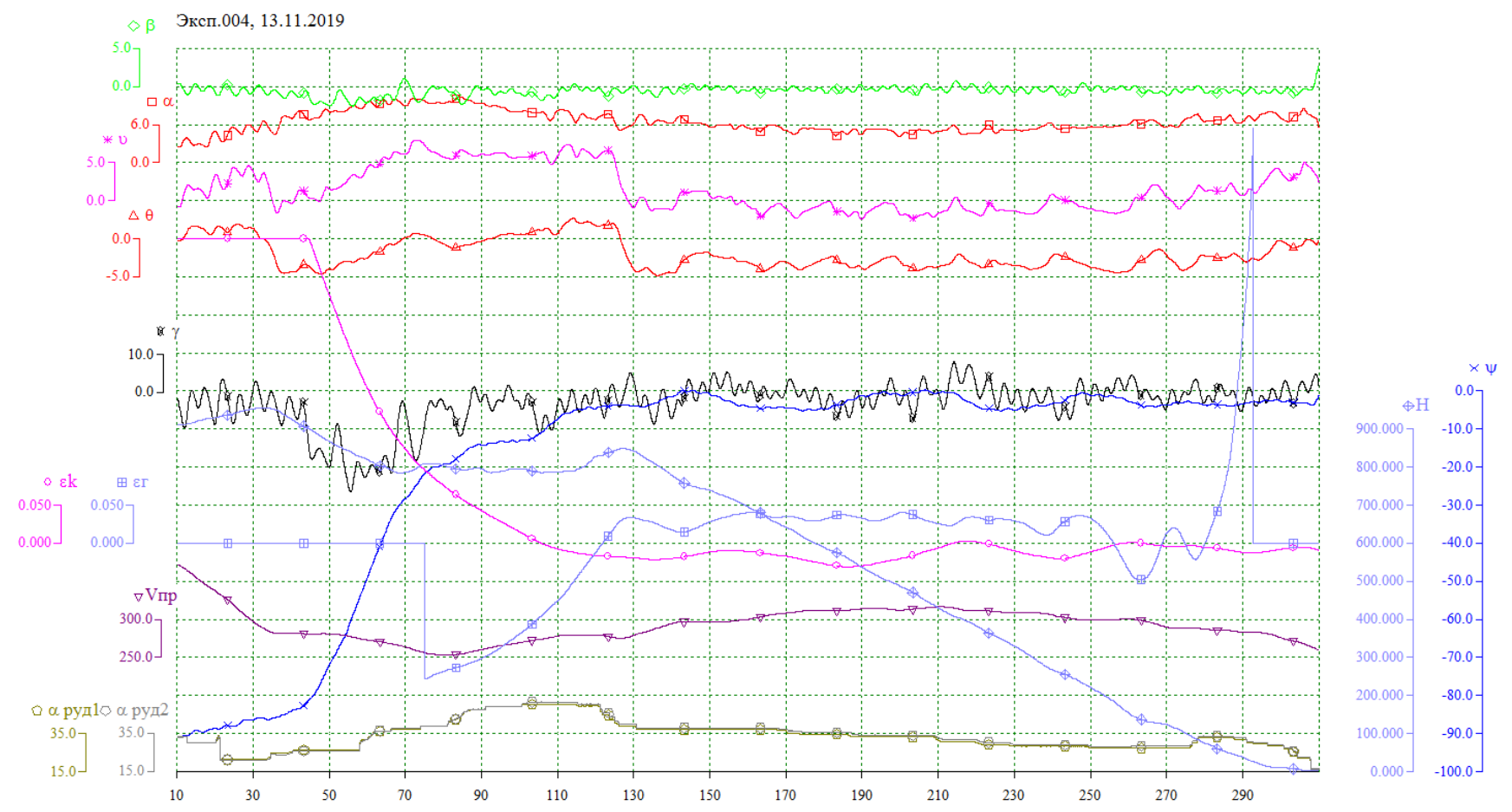

Fig. 1. IAS "Flight" with failures of the first and third fly-by-wire channels, and the control failure of the left aileron and interceptors on the port wing, where $V_{\text {is }}$ is instrument speed $(\mathrm{km} / \mathrm{h}) ; \psi$ is a magnetic course (degrees): $\Theta$ is a flightpath angle (degrees); $\Upsilon$ is a bank angle (degrees); $v$ is a pitch angle (degrees); $\alpha$ is the angle of attack (degrees); $\beta$ is a sideslip angle (degrees); $H$ is geometric altitude (m); $\varepsilon$ c is a deviation from the course equisignal zone (DDM); $\varepsilon g$ is a deviation from the glide path (DDM); $\alpha$ is the engine control lever position (degrees).

\section{PROBLEM SOLUTION}

Different data sets on bank angle trends are analysed during the statement of the research goal. This article presents illustrative examples of the obtained experimental statistics of flight results on the An-148 IAS. Let us consider flights with a total number of failures $\mathrm{n}$, when $0 \leq n \leq 2$. In this case, it is a flight without failures and with the jamming of the left slat. The initial data for the analysis is given in Table I.

The following designations are made in Table $\mathrm{I}: i$ is a measurement number, $\gamma_{i}$ is the result of the $i$-th measurement.

Let us perform the preliminary analysis of these data. The total amount of data is 54 , the average value is 0.787 , the variance is 10.58 , the standard deviation is 3.253 , and the coefficient of variation is 4.133 .
We have plotted the bank angle distribution histogram during the approach performed by a pilot between the $3^{\text {rd }}$ and $4^{\text {th }}$ turns and after the $4^{\text {th }}$ turn before landing for seven data grouping intervals (Fig. 2).

TABLE I

INITIAL DATA

\begin{tabular}{|c|c|c|c|c|c|c|c|c|c|}
\hline$i$ & 1 & 2 & 3 & 4 & 5 & 6 & 7 & 8 & 9 \\
\hline$\gamma_{i}$ & -9 & 5 & -2 & 0.5 & 5 & 2 & 0.5 & 2 & -4 \\
\hline$i$ & 10 & 11 & 12 & 13 & 14 & 15 & 16 & 17 & 18 \\
\hline$\gamma_{i}$ & -2 & -5 & 1 & -2 & 1 & 0 & -2 & -1 & -3 \\
\hline$i$ & 19 & 20 & 21 & 22 & 23 & 24 & 25 & 26 & 27 \\
\hline$\gamma_{i}$ & 2.5 & -0.5 & 0 & -2 & 0 & -1 & 4 & 0 & -8 \\
\hline$i$ & 28 & 29 & 30 & 31 & 32 & 33 & 34 & 35 & 36 \\
\hline$\gamma_{i}$ & -6 & 0 & -2 & 4 & 1 & -1 & -4 & -1 & -6 \\
\hline$i$ & 37 & 38 & 39 & 40 & 41 & 42 & 43 & 44 & 45 \\
\hline$\gamma_{i}$ & -3 & 2 & 5 & -1 & 3 & -4 & -1 & -6 & -5 \\
\hline$i$ & 46 & 47 & 48 & 49 & 50 & 51 & 52 & 53 & 54 \\
\hline$\gamma_{i}$ & 6 & 3 & -3 & -2 & 0.5 & -3 & -0.5 & -0.5 & 0 \\
\hline
\end{tabular}




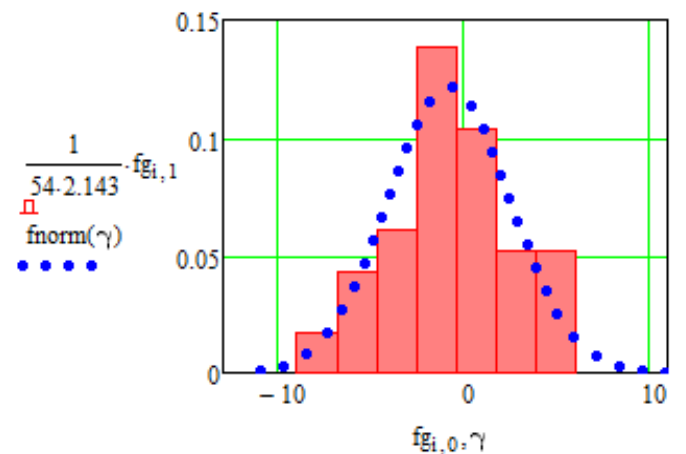

Fig. 2. Construction of a histogram of $\gamma$ values and its approximation based on the Gaussian law.

We also checked the agreement degree between theoretical and statistical distributions based on the Gaussian hypothesis using Pearson's chi-squared test $\chi^{2}$. Theoretical probabilities are calculated as follows:

$$
\begin{gathered}
p_{k}=\int_{\text {int }_{k}}^{\text {int }_{k}+\text { step }} f(x) d x, \\
f(x)=\frac{1}{\sigma \sqrt{2 \pi}} e^{-\frac{(x-m)^{2}}{2 \sigma^{2}}},
\end{gathered}
$$

where int $_{k}$ is the boundaries of group intervals, step is group interval width, $m$ is the mathematical expectation, $\sigma$ is the standard deviation.

The value of the chi-squared test is calculated according to the formula:

$$
\chi^{2}=\sum_{k=1}^{M} \frac{\left(n_{k}-N p_{k}\right)^{2}}{N p_{k}},
$$

where $n^{k}$ is the frequency of the source data falling into the group interval $k, M$ is the number of group intervals, $N$ is the sample size.

For the data in Table $\mathrm{I}$, the chi-squared test value is $\chi^{2}=2.478$.

The calculations showed that the bank angle statistical distribution $\gamma$ does not contradict the theoretical Gaussian distribution with a probability of approximately 0.7 for the number of freedom degrees $\chi^{2}$ of distribution -4 .

Earlier studies indicate that, with such a probability distribution, piloting technique quality does not deteriorate during flights without failures [15].

Let us now consider flights with complex failures $n \geq 3$. In this case, we deal with the second (right) engine failure and a failure of the second and fourth fly-by-wire channels, the lack of the right aileron control. To simplify the selection of the theoretical distribution, we change the amplitude values of the bank angles. The data for analysis is given in Table II.

The preliminary analysis of these data was performed. The total amount of data is 136 , the average value is 3.57 , the variance is 86.324 , the standard deviation is 9.291, and the coefficient of variation is 2.603 .
For eight data grouping intervals, we construct a histogram (Fig. 3). Let us check the degree to which the theoretical Gaussian distribution agrees with the statistical one according to the chi-squared test $\chi^{2}$ (Fig. 4).

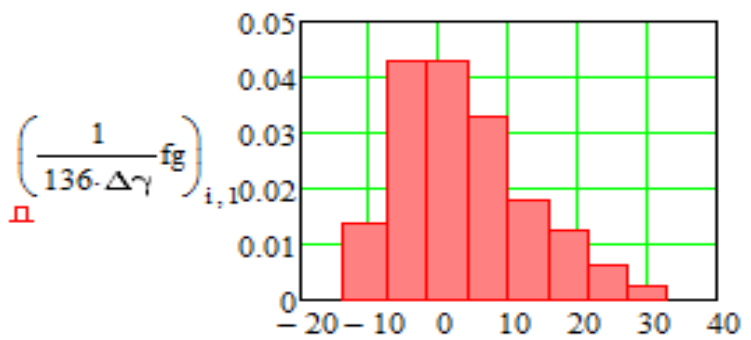

Fig. 3. Constructing a histogram of $\gamma$ values.

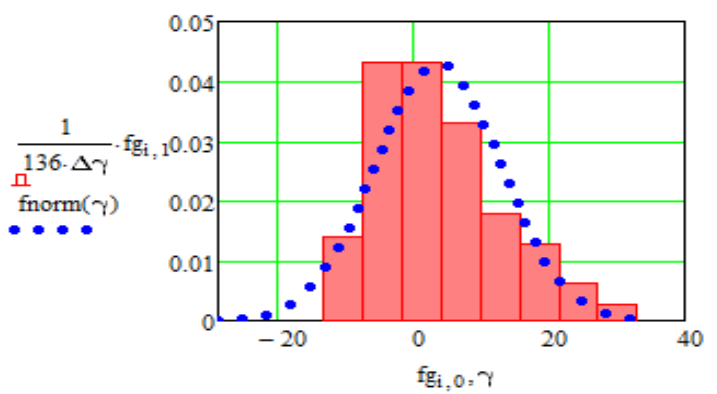

Fig. 4. Agreement verification of the theoretical Gaussian distribution with the statistical one according to the chi-squared test $\chi^{2}$.

\begin{tabular}{|c|c|c|c|c|c|c|c|c|c|c|c|c|c|}
\hline$i$ & 1 & & 2 & 3 & & 4 & & & 6 & & 7 & 8 & 9 \\
\hline$\gamma_{i}$ & 32 & & 15 & 2 & & 15 & 1 & & 13 & & 14 & 8 & 17 \\
\hline$i$ & 10 & & 11 & 1 & & 13 & & & 15 & & 16 & 17 & 18 \\
\hline$\gamma_{i}$ & 7 & & 24 & -1 & & -3 & - & & 3 & & -4 & 10 & 4 \\
\hline$i$ & 19 & & 20 & 2 & & 22 & 2 & & 24 & & 25 & 26 & 27 \\
\hline$\gamma_{i}$ & 25 & & 4 & 2 & & -10 & 2 & & 0 & & 33 & 17 & 20 \\
\hline$i$ & 28 & & 29 & 3 & & 31 & 3 & & 33 & & 34 & 35 & 36 \\
\hline$\gamma_{i}$ & 9 & & 14 & - & & 18 & - & & 4 & & -2 & 10 & 2 \\
\hline$i$ & 37 & & 38 & 3 & & 40 & 4 & & 42 & & 43 & 44 & 45 \\
\hline$\gamma_{i}$ & 3 & & -7 & -1 & & -4 & & & -7 & 1 & 10 & -9 & 2 \\
\hline$i$ & 46 & & 47 & 4 & & 49 & & & 51 & & 52 & 53 & 54 \\
\hline$\gamma_{i}$ & -10 & & 10 & - & & 17 & & & 19 & & 6 & 17 & 5 \\
\hline$i$ & 55 & & 56 & 5 & & 58 & & & 60 & 6 & 61 & 62 & 63 \\
\hline$\gamma_{i}$ & 20 & & 10 & 1 & & 3 & & & -5 & & 4 & -4 & 5 \\
\hline$i$ & 64 & & 65 & 6 & & 67 & & & 69 & & 70 & 71 & 72 \\
\hline$\gamma_{i}$ & -3 & & 9 & - & & 3 & & & 3 & & -4 & 3 & -3 \\
\hline$i$ & 73 & & 74 & 7 & & 76 & 7 & & 78 & & 79 & 80 & 81 \\
\hline$\gamma_{i}$ & 7 & & 13 & 2 & & 4 & - & & -1 & & -6 & -3 & -9 \\
\hline$i$ & 82 & & 83 & 8 & & 85 & & & 87 & & 88 & 89 & 90 \\
\hline$\gamma_{i}$ & 3 & & -1 & 7 & & 0 & & & 6 & & 5 & 9 & 3 \\
\hline$i$ & 91 & & 92 & 9 & & 94 & & & 96 & & 97 & 98 & 99 \\
\hline$\gamma_{i}$ & 4 & & -6 & - & & -9 & - & & -12 & & 2 & -3 & -13.5 \\
\hline$i$ & 100 & & 101 & 10 & & 103 & 1 & & 105 & & 06 & 107 & 108 \\
\hline$\gamma_{i}$ & 4 & & 9 & 2 & & 5 & & & 0 & & -8 & 0 & -5 \\
\hline$i$ & 109 & & 110 & 11 & & 112 & & & 114 & & 15 & 116 & 117 \\
\hline$\gamma_{i}$ & -2 & & -5 & 3 & & 0 & & & 4 & & 7 & 0 & 13 \\
\hline$i$ & 118 & & 119 & 12 & & 121 & 1 & & 123 & & 24 & 125 & 126 \\
\hline$\gamma_{i}$ & 6 & & 13 & - & & -3 & & & -2 & & -1 & -3 & 0 \\
\hline$i$ & 127 & 128 & & & 130 & & & 132 & & 33 & 13 & 135 & 136 \\
\hline$\gamma_{i}$ & -3 & -3 & & & 3 & & 2 & 3 & & -1 & -3 & 0 & -3 \\
\hline
\end{tabular}

TABLE II

INITIAL DATA 
Having performed similar calculations for the data in Table II, the value of the chi-squared test is $\chi^{2}=13.86$. Using the corresponding tables, we can conclude that the value with $\chi^{2}$ distribution and five degrees of freedom will exceed the value of 13.86 with a probability of less than 0.02 . Since this probability is too low, the Gaussian hypothesis can be rejected as implausible.

Let us verify the agreement of the theoretical lognormal distribution and the statistical one according to Pearson's chisquare test $\chi^{2}$ (Fig. 5).

The analytic expression for the lognormal distribution is the following:

$$
f(x)=\frac{1}{(x-q) \sigma_{1} \sqrt{2 \pi}} e^{-\frac{\left(\ln (x-q)-m_{1}\right)^{2}}{2 \sigma_{1}^{2}}},
$$

where $q$ is the minimum sample value, $m_{1}$ and $\sigma_{1}$ are the distribution parameters.

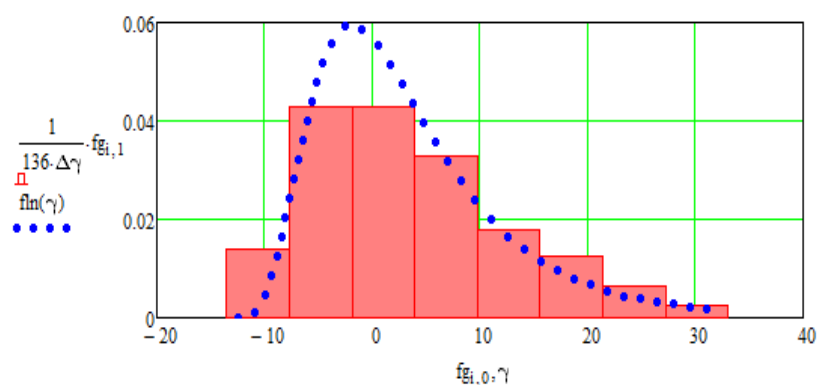

Fig. 5. Listing of the agreement verification between the theoretical lognormal distribution and the statistical one according to Pearson's chi-square test $\chi^{2}$.

For the given source data, the following values of the distribution parameters $\sigma_{1}$ and $m_{1}$ were calculated provided that $q$ is -13.5 , the statistical estimate of the mathematical expectation $m$ is 3.57 , and the statistical estimate of the standard deviation $\sigma$ is 9.291 :

$$
\begin{gathered}
\sigma_{1}=\sqrt{\ln \left(\frac{\sigma^{2}+(m-q)^{2}}{(m-q)^{2}}\right)}=0.509, \\
m_{1}=\ln (m-q)-0.5 \sigma^{2}=2.708 .
\end{gathered}
$$

Having performed similar calculations for the data in Table II for a lognormal distribution, the following value was obtained $\chi^{2}=15.835$. Using the corresponding tables, we can conclude that the value with $\chi^{2}$ distribution and four degrees of freedom will exceed 15.835 with a probability of less than 0.01 .

Since this probability is too low, the lognormal distribution hypothesis can be rejected as implausible.

Let us verify the agreement of the theoretical generalized Weibull distribution and the statistical one according to Pearson's chi-square test $\chi^{2}$ (Fig. 6).

We will also check the agreement between the theoretical generalized Weibull distribution and the statistical one according to Pearson's chi-square test.

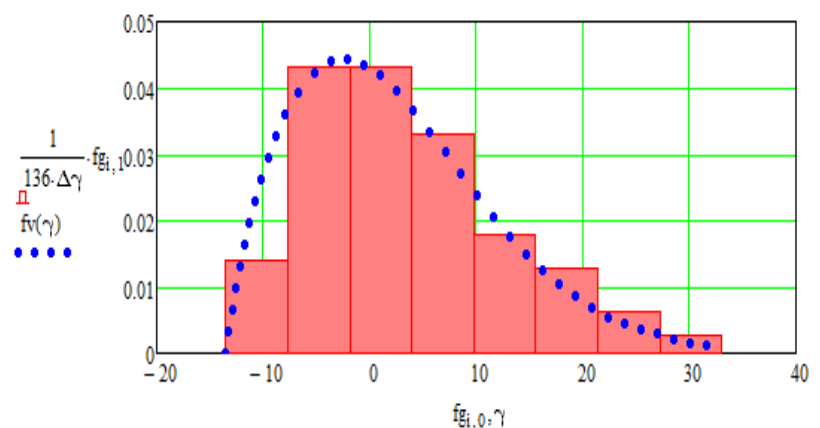

Fig. 6. Agreement verification of Weibull distribution and the statistical one according to Pearson's chi-square test $\chi^{2}$.

We will estimate the parameters of the generalized Weibull distribution based on the method described in [22]:

1. For the source data, we calculate the estimated skewness ratio according to the formula

$$
\text { Skewness }=\frac{\frac{N}{(N-1)(N-2)} \sum_{i=1}^{N}\left(x_{i}-\bar{x}\right)^{3}}{\left(\frac{1}{N-1} \sum_{i=1}^{N}\left(x_{i}-\bar{x}\right)^{2}\right)^{3 / 2}},
$$

where $\bar{x}=\frac{1}{N} \sum_{i=1}^{N} x_{i}$ is the average sample value, $N$ is the sample size.

For the studied data, it is the following:

$$
\text { Skewness }=0.808 \text {. }
$$

2. Based on the estimated skewness ratio, according to the table [10], we calculate the values of:

- form parameter:

$$
b=f(\text { Skewness })=1.75,
$$

- coefficients:

$$
\begin{aligned}
& g_{b}=f(\text { Skewness })=0.52, \\
& K_{b}=f(\text { Skewness })=0.89 .
\end{aligned}
$$

3. We estimate the scale parameter by the formula

$$
a=\frac{\sqrt{\frac{1}{N-1} \sum_{i=1}^{N}\left(x_{i}-\bar{x}\right)^{2}}}{g_{b}} .
$$

For the studied data $a$ equals 17.867 .

4. We determine the estimated scale parameter by the formulas

$$
\begin{gathered}
q^{\prime}=\bar{x}-a K_{b}, \\
q=\left\{\begin{array}{l}
q^{\prime}, \text { if } q^{\prime} \leq \min (X), \\
\min (X), \text { if } q^{\prime}>\min (X) .
\end{array}\right.
\end{gathered}
$$

In this case, $q^{\prime}=-12.322, \min (X)=-13.5$; therefore, $q=-13.5$. 
Based on the calculations for the data in Table II, in case of the generalized Weibull distribution, the value of the chi-squared test is $\chi^{2}=4.265$. Using the corresponding tables, we can conclude that the value with $\chi^{2}$ distribution and four degrees of freedom will exceed the given value of 4.265 with a probability of less than 0.4. Since this probability is quite high, the generalized Weibull distribution hypothesis can be considered as the one not contradicting the experimental data.

It should be noted that these failures complicate aircraft control. It is connected with the control system and the influence of aerodynamic forces. However, when "flying" with the same individual failures and in combination with other failures, the distribution law is normal.

This indicates an increase in the pilot's psychophysiological tension and the need for IAS exercises to learn how to deal with an increase in AAOP. As can be seen in Fig. 1, on the glide path, the bank angle does not exceed $12^{\circ}$ when $n \geq 3$, which with a large margin corresponds to the norms of the flight operations manual. However, with further flight task complication, bank increases to $33^{\circ}$.

We will carry out a synthesis of algorithms for detecting the presence in bank angle trends of components indicating complex failures and possible further severe aircraft operation complications. Let us suppose that there is hypothesis $H_{0}$ (there are no problems during the flight) and alternative hypothesis $H_{1}$ (there are complications). In general, in case of $H_{0}$, the probability density function of the bank angle is Gaussian, and in case of $H_{1}$ this distribution density has the form of a generalized Weibull distribution.

To solve the detection problem in this case, the analytics will be difficult, so we make the following assumption. Based on the analysis of the bank angle parameter in Fig. 1, we suggest that for complex failures we have a model for changing the bank angle in the form of an additive combination of two components: Gaussian noise and harmonic oscillations.

Then an indicator of complex failures is the presence of a sinusoidal signal in the mixture.

To check the detection quality, we will simulate the original signals.

We will model a normal situation without failures. This situation corresponds to the normal Gaussian noise. The signal implementation in case of a normal situation is shown in Fig. 7. Let us model a flight in difficult conditions, in which the psychophysiological tension in the human operator takes place. In this case, we use a discrete sinusoid as an information signal with the amplitude $U=5$ and the period $T=4$. A mixture of the information signal and the normal Gaussian noise (the situation with severe aircraft operation complications) is shown in Fig. 8.

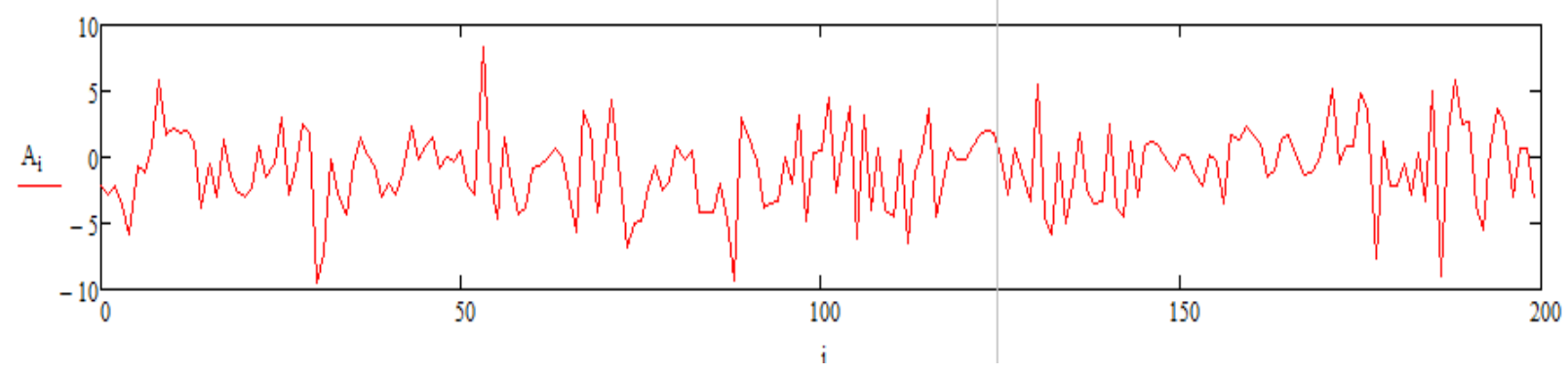

Fig. 7. Graph modelling a random function of a parameter in flight without failures.

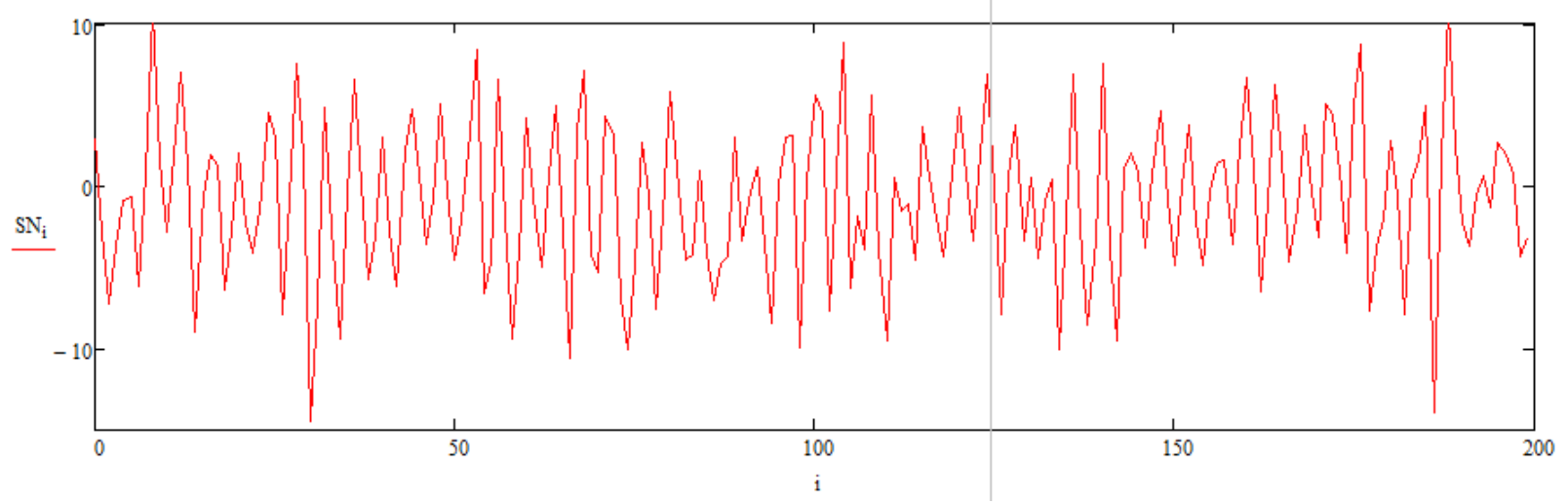

Fig. 8. Graph modelling a random function of a parameter in abnormal aircraft operation conditions.

Let us mathematically synthesize the signal detection algorithm. For the assumptions made, the detection problem comes down to the verification of simple hypothesis $H_{0}$ that the sample implementation is described by a multidimensional Gaussian distribution, against the simple alternative $H_{1}$ that the sample implementation contains a useful sinusoidal signal. In 
this case, the samples are considered independent random variables. Then

$$
\begin{gathered}
f\left(x_{1}, x_{2}, \ldots, x_{N} / H_{0}\right)=\frac{1}{(\sigma \sqrt{2 \pi})^{N}} e^{-\frac{\sum_{i=1}^{N}\left(x_{i}-\bar{x}\right)^{2}}{2 \sigma^{2}},} \\
f\left(x_{1}, x_{2}, \ldots, x_{N} / H_{1}\right)=\frac{1}{(\sigma \sqrt{2 \pi})^{N}} e^{-\frac{\sum_{i=1}^{N}\left(x_{i}-\bar{x}-S_{i}\right)^{2}}{2 \sigma^{2}}},
\end{gathered}
$$

where $\sigma$ is the standard deviation, and $S_{i}$ is known samples of the sinusoidal signal.

We consider the parameters $\bar{x}$ and $\sigma$ as known as they can be identified based on the monitoring process results with no failures.

The likelihood ratio, which determines the decision statistics, is calculated by the formula

$$
l\left(x_{1}, x_{2}, \ldots, x_{N}\right)=\frac{f\left(x_{1}, x_{2}, \ldots, x_{N} / H_{1}\right)}{f\left(x_{1}, x_{2}, \ldots, x_{N} / H_{0}\right)} .
$$

Consequently,

$$
\begin{aligned}
& l\left(x_{1}, x_{2}, \ldots, x_{N}\right)=\frac{\frac{1}{(\sigma \sqrt{2 \pi})^{N}} e^{-\frac{\sum_{i=1}^{N}\left(x_{i}-\bar{x}-S_{i}\right)^{2}}{2 \sigma^{2}}}}{\frac{1}{(\sigma \sqrt{2 \pi})^{N}} e^{-\frac{\sum_{i=1}^{N}\left(x_{i}-\bar{x}\right)^{2}}{2 \sigma^{2}}}}= \\
& =e^{\frac{-\sum_{i=1}^{N}\left(x_{i}-\bar{x}-S_{i}\right)^{2}+\sum_{i=1}^{N}\left(x_{i}-\bar{x}\right)^{2}}{2 \sigma^{2}}} .
\end{aligned}
$$

To simplify mathematical calculations, we will use the loglikelihood ratio, then

$$
\begin{gathered}
\ln l\left(x_{1}, x_{2}, \ldots, x_{N}\right)=\ln e^{\frac{-\sum_{i=1}^{N}\left(x_{i}-\bar{x}-S_{i}\right)^{2}+\sum_{i=1}^{N}\left(x_{i}-\bar{x}\right)^{2}}{2 \sigma^{2}}}= \\
=\frac{\sum_{i=1}^{N}\left(2 S_{i}\left(x_{i}-\bar{x}\right)-S_{i}^{2}\right)}{2 \sigma^{2}} .
\end{gathered}
$$

Consequently,

$$
\ln l\left(x_{1}, x_{2}, \ldots, x_{N}\right)=\frac{1}{\sigma^{2}} \sum_{i=1}^{N} S_{i}\left(x_{i}-\bar{x}\right)-\frac{1}{2 \sigma^{2}} \sum_{i=1}^{N} S_{i}^{2} .
$$

According to the Neyman-Pearson criterion, the decision threshold $V$ is selected based on the solution of the following equation in case there is no sinusoidal oscillation in the analysed mixture:

$$
\operatorname{Pr}\left(\frac{1}{\sigma^{2}} \sum_{i=1}^{N} S_{i}\left(x_{i}-\bar{x}\right)-\frac{1}{2 \sigma^{2}} \sum_{i=1}^{N} S_{i}^{2} \geq V / H_{0}\right)=\alpha .
$$

In this case, the decision threshold was determined by statistical modelling based on the Monte Carlo method. For a given sample size and the parameter $\alpha=0.025$, as well as the parameters of the detected sinusoidal oscillation, $V \approx 0$.

In case of an optimal Bayesian detector, the threshold can be determined according to the following procedure. Let us rewrite the decisive statistics in the form

$$
\frac{1}{\sigma^{2}} \sum_{i=1}^{N} S_{i}\left(x_{i}-\bar{x}\right)=\ln l\left(x_{1}, x_{2}, \ldots, x_{N}\right)+\frac{1}{2 \sigma^{2}} \sum_{i=1}^{N} S_{i}^{2} .
$$

Then

$$
\begin{gathered}
\frac{1}{\sigma^{2}} \sum_{i=1}^{N} S_{i}\left(x_{i}-\bar{x}\right)=\ln \mu c+\frac{1}{2 \sigma^{2}} \sum_{i=1}^{N} S_{i}^{2} . \\
\sum_{i=1}^{N} S_{i}\left(x_{i}-\bar{x}\right)=\sigma^{2} \ln \mu c+0.5 \sum_{i=1}^{N} S_{i}^{2},
\end{gathered}
$$

where $\mu=\frac{q}{p}, c=\frac{C_{01}-C_{00}}{C_{10}-C_{11}}, q$ and $p$ are the prior probabilities of the hypothesis and the alternative, $C_{00}$ together with $C_{11}$ are costs associated with correct decisions, $C_{01}$ and $C_{11}$ are costs associated with erroneous decisions (in this case, $C_{01}>C_{00} \geq 0$ and $\left.C_{10}>C_{11} \geq 0\right)$.

Thus, the decision threshold for an optimal Bayesian detector is the following:

$$
V=\sigma^{2} \ln \mu c+0.5 \sum_{i=1}^{N} S_{i}^{2}
$$

and the decision rule is:

1) to accept $H_{0}$, if $\sum_{i=1}^{N} S_{i}\left(x_{i}-\bar{x}\right)<V$;

2) to accept $H_{1}$, if $\sum_{i=1}^{N} S_{i}\left(x_{i}-\bar{x}\right) \geq V$.

Let us consider a method that meets the Neyman-Pearson criterion. If the decision statistics DS exceeds a threshold, then in mixed functions there is a sinusoidal signal.

We will carry out calculations for the simulation results illustrated in Figs. 7, 8.

If there is no sinusoidal signal, we obtain the value of decision statistics $D S=-130.782$. Let us consider statistics with a sinusoidal signal, i.e., in the mixed function decision statistics $D S=146.997$ exceeds the allowable threshold $V \approx 0$.

The analysis of the proposed algorithm is carried out based on the Monte Carlo statistical simulation. During the simulation, the following characteristics are calculated:

1) operating characteristics;

2) probabilities of type I and type II errors.

At the first simulation stage, statistical data for hypothesis $H_{0}$ are generated for the given number of procedure repetitions. For a simulation procedure, the events of the exceeded or nonexceeded threshold are determined. After that, the total quantity of threshold-exceeding events is calculated. The ratio of this quantity to the number of procedure repetitions is the probability $\alpha^{*}$ of type I error. 
At the second simulation stage, statistical data for the alternative $H_{1}$ are generated. The ratio of the total quantity of non-exceeded-threshold events to the number of procedure repetitions is the probability $\beta^{*}$ of type I error.

The operating characteristic is calculated in the following way. For different values of information signal amplitude, the correct detection probability $D^{*}$ is calculated. After that, the corresponding dependence of probability $D^{*}$ on signal amplitude is plotted.

Multiple simulations have confirmed the effective detection of a sinusoidal signal for a given interference situation. Monte Carlo statistical simulation results for 10000 repetition procedures show that this detection algorithm is characterised by the following probabilities of erroneous decisions $\alpha^{*}=0.0263$ and $\beta^{*}=0.0011$.

Let us consider the Bayesian optimal detector with the following a priori data:

- the probability of an emergency situation $p=0.001$, and the probability of abnormal operations $q=0.999$;

- cost matrix:

$$
\begin{aligned}
& C_{00}=0, \quad C_{01}=10, \\
& C_{10}=100, \quad C_{11}=0 .
\end{aligned}
$$

Let us calculate the signal threshold

$$
V_{p}=\sigma^{2} \cdot \ln \left(\frac{q}{p} \cdot \frac{C_{01}-C_{00}}{C_{10}-C_{11}}\right)+0.5 \cdot \sum_{i=0}^{N-1}\left(S_{i}\right)=129.1 .
$$

We will carry out calculations for the simulation results shown in Figs. 7, 8.

In the absence of a sinusoidal signal, the value is the following:

$$
D S=\sum_{i=0}^{N}\left[S_{i}\left(A_{i}-m\right)\right]=72.975 .
$$

Decision statistics is less than the threshold, so we can conclude that there is no sinusoidal signal, and only noise is present. We then consider statistics with a sinusoidal signal. Wherein:

$$
D S=\sum_{i=0}^{N}\left[S_{i}\left(A_{i}-m\right)\right]=257.3 .
$$

Monte Carlo statistical modelling results for 10000 repetition procedures show that this detection algorithm is characterised by the following probabilities of erroneous decisions $\alpha=0.0012$ and $\beta=0.0349$.

Let us consider the actual bank angle of the IAS "flight" $(n \geq 3)$ with a full fly-by-wire failure (a failure of all four channels, i.e., undamped backup control) and the second (starboard) engine failure (Table III). Figure 9 shows a bank angle graph with fixing the amplitudes.

Decision statistics for the first method according to the Neyman-Pearson criterion (decision threshold $V \approx 0$ )

$$
D S=\sum_{i=0}^{N-1} \frac{2 S_{i} \cdot\left(\xi_{i}-m\right)-\left(S_{i}\right)^{2}}{2 \cdot \sigma^{2}}=13.333
$$

For the second method according to the Bayesian approach

$$
\begin{gathered}
V_{p}=\sigma^{2} \ln \left(\frac{q}{p} \cdot \frac{C 01-C 00}{C 10-C 11}\right)+0.5 \sum_{i=0}^{N-1}\left(S_{i}\right)=356.438 . \\
D S=\sum_{i=0}^{N-1}\left[S_{i}\left(\zeta_{i}-m\right)\right]=435 .
\end{gathered}
$$

Thus, the two considered algorithms based on the NeymanPearson criterion and the optimal Bayesian criterion revealed the presence of a determinate sinusoidal component in this IAS "flight".

TABLE III

BANK ANGLE DATA

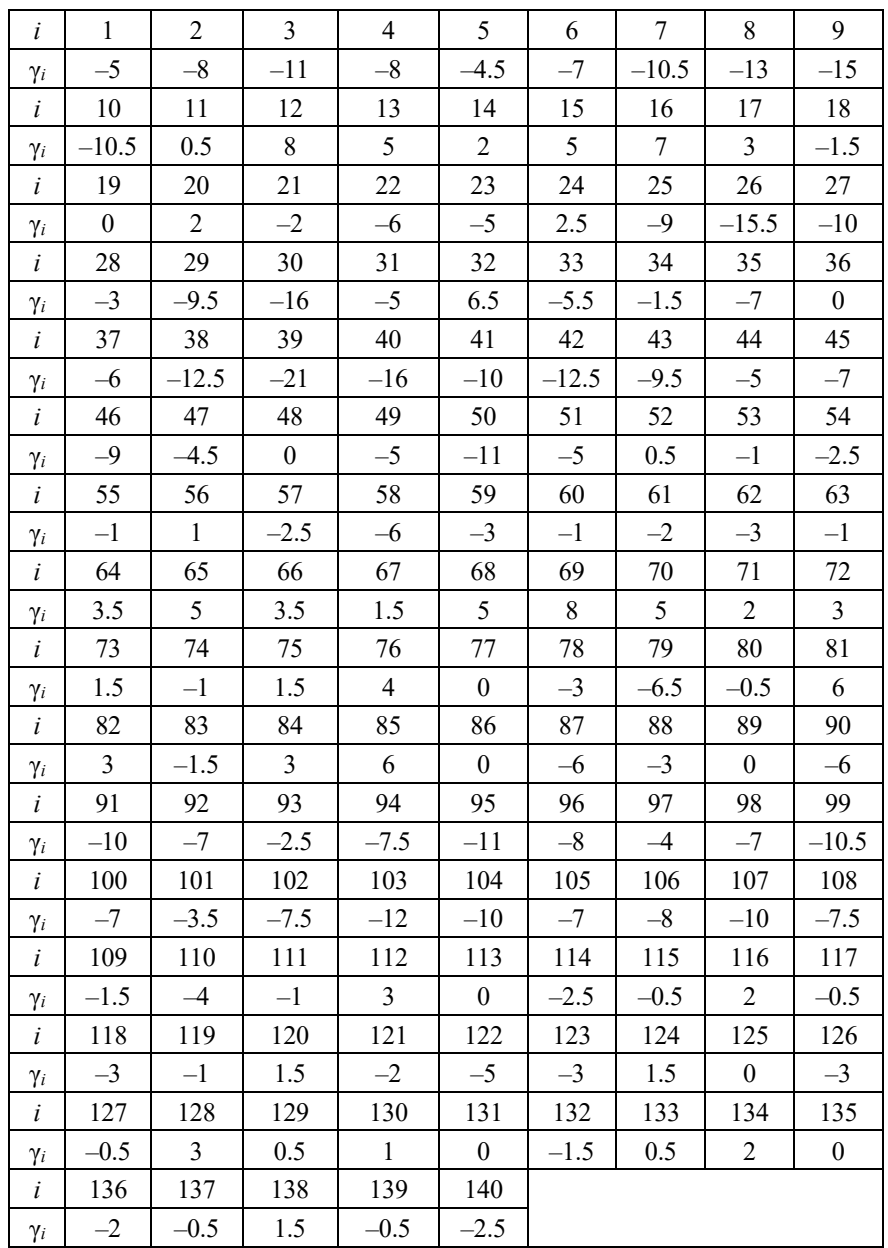

To analyse the efficiency of the proposed algorithms, the operating characteristic was calculated. The characteristic was constructed based on Monte Carlo statistical modelling results for 10000 repetition procedures. During statistical modelling the probability of correct detection was calculated for different values of informational signal amplitude. 
The operating characteristics for two algorithms of detection are shown in Fig. 10. The figure also shows that operating characteristics have the same increasing trend.

To assess the quality of pilots' training for abnormal flight operations, it is advisable to have a statistical data bank of the results of the developed algorithms. The comparison of pilots' training quality should be based on the results obtained during the IAS "flight" with the same set of failures.

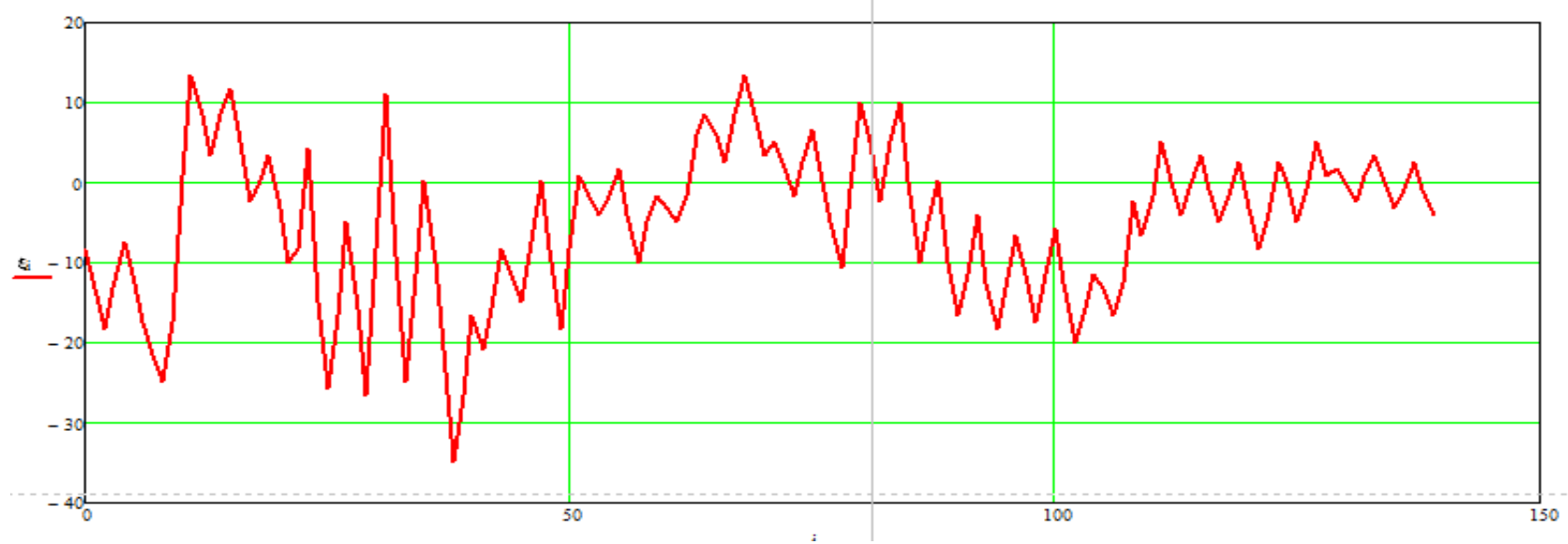

Fig. 9. Bank angle graph versus the time of the IAS "flight" with a full fly-by-wire failure (undamped backup control) and the second (starboard) engine failure, where the amplitude of the parameter is $U=3$, the period is $T=4$.

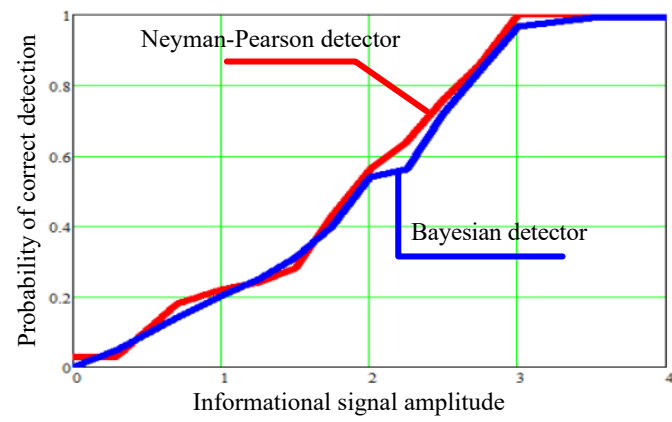

Fig. 10. The operating characteristics for two algorithms of detection.

\section{CONCLUSION}

The issues of "flight" data processing on integrated aircraft simulators are an urgent scientific task in terms of improving methods and tools of flight crew training. Modern simulators allow pilots' exercises in both ordinary "flight" conditions and complex ones with more than two failures. An analysis of the trends of a number of "flight" parameters shows that data processing should be statistical since the implementation of the "flight" parameters is generally a random process.

Based on the undertaken studies on the An-148 IAS, it was found that without failures or in case of a single-event upset, the statistical distribution of such an important parameter as the bank angle did not contradict the Gaussian law. With the simultaneous occurrence of more than two serious failures, the statistical distribution of the bank angle did not contradict the generalized Weibull distribution. During such "flights", the quality of piloting technique deteriorates. The level of the pilot's psychophysiological tension increases. Cases, when flight parameters exceed the permissible values, are more frequent. These standards are set out in the flight manual for this type of aircraft.

To automate the detection process of piloting technique quality deterioration in "complex" failures, two detection algorithms were developed based on the Neyman-Pearson criterion and the optimal Bayesian criterion. In the synthesis of detection algorithms, the assumption was used that a harmonic component was found in the bank angle trend with "complex" failures. This allowed simplifying the analytical form of data processing.

It is necessary to create a database of flight processing results based on the developed algorithms. For a comparative assessment of crew training level, it is necessary to have a unified list of the failure complex in the IAS flight control system. Failures that do not affect the aircraft dynamics and in case there are duplicate devices when there is an avionics system failure are more adequate.

The main objective of such training is to teach the crew to take adequate actions when facing increased psychophysiological tension during abnormal aircraft operations.

Thus, the scientific novelty of this research is associated with the synthesis of a new data processing method to detect pilots' individual properties negatively affecting the quality of piloting technique. In addition, based on the obtained results, new methods can be developed and implemented in the pilots' training process.

In general, the results obtained in the framework of the research can be used to improve An-148 IAS software in order to automate the decision-making process on the level of aircraft pilot' training. 


\section{REFERENCES}

[1] A. G. Taranenko, Y. I. Gabrousenko, A. G. Holubnychyi and I. A. Slipukhina, "Estimation of Redundant Radionavigation System Reliability", Proceedings IEEE 5th International Conference on Methods and Systems of Navigation and Motion Control, October 1618, Kyiv, Ukraine, pp. 28-31. https://doi.org/10.1109/MSNMC.2018.8576282

[2] T. Shmelova, Y. Sikirda, C. Scarponi and A. Chialastri, "Deterministic and Stochastic Models of Decision Making in Air Navigation SocioTechnical System," Proceedings ICT in Education, Research and Industrial Applications. Integration, Harmonization and Knowledge Transfer; Part III: Theory of Reliability and Markov Modelling for Information Technologies (TheRMIT 2018), May 14-17, Kyiv, Ukraine, 2018, vol. II, pp. 649-656.

[3] T. Shmelova, Y. Sikirda and M. Kasatkin, "Applied Artificial Intelligence for Air Navigation Sociotechnical System Development", Proceedings ICT in Education, Research and Industrial Applications. Integration, Harmonization and Knowledge Transfer; Part V: Posters, June 12-15, Kherson, Ukraine, 2019, pp. 470-475.

[4] ICAO Circular 240-AN/144. Human factors digest No 7. Investigation of Human Factors in Accidents and Incidents, 1993, $76 \mathrm{p}$.

[5] Y. Hryshchenko, "Scientific Research on the Anti-stress Preparation of Specialists in a Quarter Century", Proceedings of the National Aviation University, 2014, vol. 58, no. 1, pp. 53-58. https://doi.org/10.18372/2306-1472.58.6692

[6] R. L. Helmreich and J. M. Davies, "3 Human Factors in the Operating Room: Interpersonal Determinants of Safety, Efficiency and Morale", Bailliere's clinical anaesthesiology: Quality Assurance and Risk Management in Anaesthesia, 1996, vol. 10, no. 2, pp. 277-295. https://doi.org/10.1016/S0950-3501\%2896\%2980017-1

[7] A. Goncharenko, "Aircraft operation depending upon the uncertainty of maintenance alternatives," Aviation, 2017, vol. 21, no. 4, pp. 126131. https://doi.org/10.3846/16487788.2017.1415227

[8] G. Cowan, Statistical Data Analysis. Clarendon Press, Oxford, 1998, $198 \mathrm{p}$.

[9] L. V. Berezkina and V. P. Klyauze, Ergonomics. Minsk, Higher School, 2013, 432 p. ISBN 978-985-06-2309-6 (in Russian)

[10] V. P. Strelnikov and A. V. Fedukhin, Assessment and prediction of the reliability of electronic elements and systems. Kyiv, Logos, 2002, p. 487. (in Ukrainian)

[11] V. Strelnikov, "The Status and Prospects of Reliability Technology," RAC Journal, 2001, vol. 1, pp. 1-4. (in Russian).

[12] S. Lienkov, G. Zhyrov, O. Sieliukov, I. Tolok, Al-Sharify Mushtag Talib and I. Pampuha, "Calculation of reliability indicators of unmanned aerial vehicle class " $\mu$ " taking into account operating conditions at the design stage," Proceedings IEEE 5th International Conference Actual Problems of Unmanned Aerial Vehicles Developments, October 22-24, Kyiv, Ukraine, 2019, pp. 52-56. https://doi.org/10.1109/APUAVD47061.2019.8943876

[13] R. Volianskyi, O. Sadovoi, N. Volianska and O. Sinkevych, "Construction of Parallel Piecewise-Linear Interval Models for Nonlinear Dynamical Objects," Proceedings 9th International Conference on Advanced Computer Information Technologies, June 5-7, Ceske Bidejovice, Czech Republic, 2019, pp. 97-100. https://doi.org/10.1109/ACITT.2019.8779945

[14] O. Solomentsev, M. Zaliskyi, T. Herasymenko and Y. Petrova, "Method for Changepoint Detection with Sample Size Accumulation During Radio Equipment Operation," The Scientific Journal of Riga Technical University - Electrical, Control and Communication Engineering, 2020, vol. 16, no. 1, pp. 23-29. https://doi.org/10.2478/ecce-2020-0004

[15] Y. V. Hryschchenko, "Analysis of changes in the dynamic stereotype of pilots during flight training on an integrated simulator of an airplane," Cybernetics and computing engineering, NAS of Ukraine, 2004, vol. 142, pp. 35-40. (in Russian)

[16] I. G. Prokopenko, S. V. Migel and K. I. Prokopenko, "Signal modeling for the efficient target detection tasks," Proceedings International Radar Symposium, June 19-21, Dresden, Germany, 2013, vol. II, pp. 976-982.
[17] O. Solomentsev, M. Zaliskyi, T. Herasymenko, O. Kozhokhina and Yu. Petrova "Data Processing in Case of Radio Equipment Reliability Parameters Monitoring", Proceedings Advances in Wireless and Optical Communications, November 15-16, Riga, Latvia, 2018, pp. 219-222. https://doi.org/10.1109/RTUWO.2018.8587882

[18] N. S. Kuzmenko, I. V. Ostroumov and K. Marais, "An accuracy and availability estimation of aircraft positioning by navigational aids," Proceedings IEEE International Conference on Methods and Systems of Navigation and Motion Control (MSNMC 2018), October 16-18, Kyiv, Ukraine, 2018, pp. 36-40. https://doi.org/10.1109/MSNMC.2018.8576276

[19] V. P. Kharchenko, N. S. Kuzmenko and I. V. Ostroumov, "Identification of unmanned aerial vehicle flight situation," Proceedings IEEE 4th International Conference on Actual Problems of Unmanned Aerial Vehicles Developments (APUAVD), October 17-19, Kyiv, Ukraine, 2017, pp. 116-120. https://doi.org/10.1109/APUAVD.2017.8308789

[20] O. V. Kutsenko, S. I. Ilnytska, V. M. Kondratyuk and V. V. Konin, "Unmanned aerial vehicle position determination in GNSS landing system," Proceedings IEEE 4th International Conference on Actual Problems of Unmanned Aerial Vehicles Developments, October 1719, Kyiv, Ukraine, 2017, pp. 79-83. https://doi.org/10.1109/APUAVD.2017.8308781

[21] V. Ulansky and I. Terentyeva, "Availability Assessment of a Telecommunications System with Permanent and Intermittent Faults", Proceedings IEEE First Ukraine Conference on Electrical and Computer Engineering, May 29 - June 2, Kyiv, Ukraine, 2017, pp. 908 911. https://doi.org/10.1109/UKRCON.2017.8100386

[22] National State Standard 11.007-75, "Applied statistics. Point and interval estimators for parameters of Weibull distribution". (in Russian)

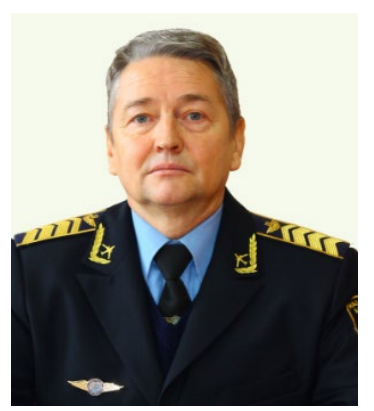

Yurii Hryshchenko was born in 1958 in the military town of Gorelovo, Leningrad (St. Petersburg), the Russian Federation. He received his M. Sc. degree in 1987 in the operation of aviation equipment from Kyiv Institute of Civil Aviation, Ukraine and a PhD degree in 1995 in aircraft equipment operation from Kyiv International University of Civil Aviation University, Ukraine.

He is currently an Associate Professor of the Department of Avionics, National Aviation University. He has authored 45 published papers on human factors and avionics reliability. His research interests include flight safety and reliability of technical and ergatic systems. Address: National Aviation University, Avionics Department, Lubomir Huzar Ave. 1, off. 5-405, Kyiv, Ukraine.

E-mail: hryshchenko18@nau.edu.ua ORCID ID: https://orcid.org/0000-0002-1318-9354

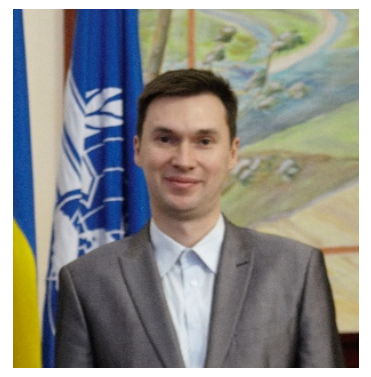

Maksym Zaliskyi was born in 1984 in Kyiv (Ukraine). He received his B. Sc. and $\mathrm{M}$. Sc. degrees in radio engineering from the National Aviation University, Ukraine, in 2005 and 2007, respectively. He obtained a PhD degree in 2012 in operation and repair of transport means from the National Aviation University. He is currently an Associate Professor of the Department of Telecommunication and Radioelectronics Systems, the National Aviation University. He has authored 130 published papers on maintenance and operation of radio equipment, statistical data processing and heteroscedasticity analysis. His research interests include design and improvement of the operation system for radio equipment, statistical analysis of operational data.

Address: National Aviation University, Department of Telecommunication and Radioelectronic Systems, Lubomir Huzar Ave. 1, off. 3-314, Kyiv, Ukraine.

E-mail: mzaliskyi@nau.edu.ua

ORCID iD: https://orcid.org/0000-0002-1535-4384 


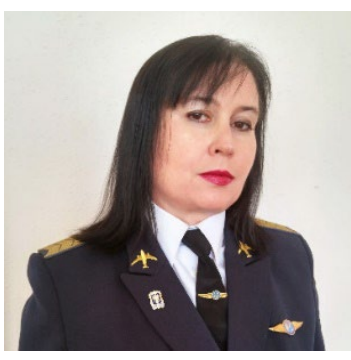

Svitlana Pavlova was born in 1966 in Kyiv (Ukraine). She received her M. Sc. degree in automated control systems from Order of the Red Banner of Labor Civil Engineering Institute, Ukraine, in 1988, and $\mathrm{PhD}$ and Dr. sc. ing. degrees in systems and processes of control from the National Aviation University, Ukraine, in 2000 and 2008, respectively.

She is currently a Head of the Department of Avionics, National Aviation University. She has authored more than 100 published papers on the control of complex nonlinear dynamic systems. Her research interests are complex non-linear dynamic systems, ergatic systems, conflict systems, analysis and synthesis of integrated control of complex distributed dynamic networkcentric systems.

Address: National Aviation University, Department of avionics, 03058, Ukraine, Kyiv, Lubomir Husar Ave. 1, off. 5-402, Kyiv, Ukraine.

E-mail: psv@nau.edu.ua

Scopus Author ID: 15837938800

ORCID iD: http://orcid.org/0000-0003-4012-9821

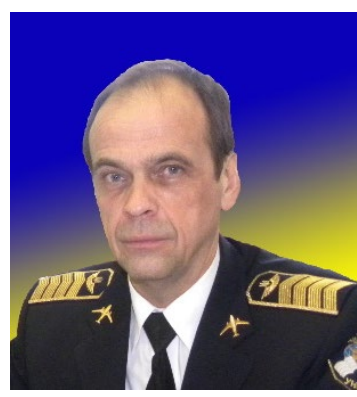

Oleksandr Solomentsev was born in 1949 in Simferopol (Ukraine). He received his $\mathrm{M}$. Sc. degree in operation of aviation radio equipment from Kyiv Institute of Civil Aviation, Ukraine, in 1972, and $\mathrm{PhD}$ and Dr. sc. ing. degrees in aircraft equipment operation from Kyiv Institute of Civil Aviation, Ukraine, in 1981 and 1988, respectively.

$\mathrm{He}$ is currently a Professor of the Department of Telecommunication and Radioelectronic Systems, the National Aviation University. He has authored more than 200 published papers on maintenance and operation of radio equipment, statistical data processing and reliability theory. His research interests include design and improvement of the operation system for radio equipment, statistical analysis of operational data.

Address: National Aviation University, Department of Telecommunication and Radioelectronic Systems, Lubomir Husar Ave. 1, off. 3-314, Kyiv, Ukraine.

E-mail: avsolomentsev@ukr.net

ORCID iD: https://orcid.org/0000-0002-3214-6384

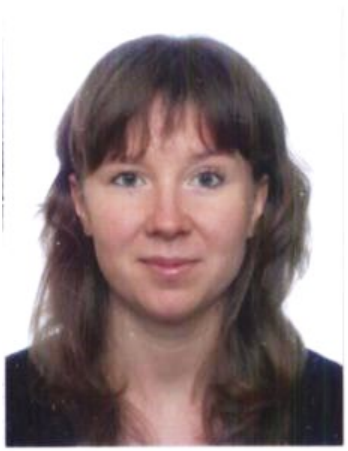

Tatiana Fursenko was born in 1992 in Kyiv (Ukraine). She holds an M. A. degree with distinction in English Philology from Borys Grinchenko Kyiv University (2014). In 2018, she defended a PhD thesis in "Theory and Methods of Vocational Training".

Tatiana Fursenko is currently an Associate Professor of the Aviation English Department, the National Aviation University. She has authored more than 30 published papers on theory, methodology and tools underlying specialists' professional training and English teaching methodology. Her research interests include aviation professionals' training, ESP teaching methods.

Address: National Aviation University, Department of Aviation English, Lubomir Husar Ave. 1, off. 11-413, Kyiv, Ukraine.

E-mail: tanya kostylova@ukr.net

ORCID iD: https://orcid.org/0000-0001-7192-8867 